\title{
Essential roles for the splicing regulator nSR100/SRRM4 during nervous system development
}

\author{
Mathieu Quesnel-Vallières, ${ }^{1,2,3}$ Manuel Irimia, ${ }^{2,4}$ Sabine P. Cordes, ${ }^{1,3}$ and Benjamin J. Blencowe ${ }^{1,2}$ \\ ${ }^{1}$ Department of Molecular Genetics, University of Toronto, Toronto, Ontario M5S 1A8, Canada; ${ }^{2}$ Donnelly Centre, University of \\ Toronto, Toronto, Ontario M5S 3E1, Canada; ${ }^{3}$ Lunenfeld-Tanenbaum Research Institute, Mount Sinai Hospital, Toronto, Ontario \\ M5G 1X5, Canada
}

\begin{abstract}
Alternative splicing (AS) generates vast transcriptomic complexity in the vertebrate nervous system. However, the extent to which trans-acting splicing regulators and their target AS regulatory networks contribute to nervous system development is not well understood. To address these questions, we generated mice lacking the vertebrateand neural-specific Ser/Arg repeat-related protein of $100 \mathrm{kDa}$ (nSR100/SRRM4). Loss of nSR100 impairs development of the central and peripheral nervous systems in part by disrupting neurite outgrowth, cortical layering in the forebrain, and axon guidance in the corpus callosum. Accompanying these developmental defects are widespread changes in AS that primarily result in shifts to nonneural patterns for different classes of splicing events. The main component of the altered AS program comprises 3- to 27-nucleotide (nt) neural microexons, an emerging class of highly conserved AS events associated with the regulation of protein interaction networks in developing neurons and neurological disorders. Remarkably, inclusion of a 6-nt, nSR100-activated microexon in Unc13b transcripts is sufficient to rescue a neuritogenesis defect in nSR100 mutant primary neurons. These results thus reveal critical in vivo neurodevelopmental functions of nSR100 and further link these functions to a conserved program of neuronal microexon splicing.
\end{abstract}

[Keywords: alternative splicing; SR proteins; nervous system development; microexons]

Supplemental material is available for this article.

Received November 18, 2014; revised version accepted February 27, 2015.

Proper development and function of the mammalian nervous system depend on the tight coordination of multiple layers of gene regulation. During development, neurons progress through maturation stages to acquire their subtype-specific functions (Gao et al. 2013). For example, neurons born in the subventricular zone (SVZ) of the embryonic cortex use endocrine and exocrine cues while migrating dorsally to establish and populate specific cortical layers. Similarly, neuronal projections in the brain and periphery rely on successive adjustments of intrinsic to extrinsic factors to arrive at their targets. Considerable remodeling of the cytoskeleton, vesicular transport, and other subcellular processes allows neurons to achieve their designated morphologies and functions. While similar repertoires of genes are associated with these processes, it is becoming apparent that extensive variation at the level of post-transcriptional regulation generates the remarkable transcriptomic and proteomic diversity required for establishing biological complexity during verte-

${ }^{4}$ Present address: EMBL/CRG Research Unit in Systems Biology, Centre for Genomic Regulation (CRG), Barcelona 08003, Spain Corresponding authors: b.blencowe@utoronto.ca, cordes@lunenfeld.ca Article is online at http://www.genesdev.org/cgi/doi/10.1101/gad.256115 114. brate nervous system development (Li et al. 2007; Norris and Calarco 2012; Lipscombe et al. 2013a; Zheng and Black 2013).

Alternative splicing (AS) is the process by which different pairs of splice sites are selected to produce multiple transcripts from a single gene. It is controlled by the concerted action of multiple cis-acting motifs and cognate trans-acting factors that promote or repress the assembly of productive splicing complexes (spliceosomes) at splice sites (Chen and Manley 2009; Braunschweig et al. 2013). Widely expressed and tissue-restricted RNA-binding proteins combine to regulate AS decisions via positive- and negative-acting cis motifs located in exons or flanking introns, referred to as splicing enhancers and silencers, respectively. AS represents a major source of biological diversity that likely afforded the evolution of complexity associated with the development and function of the vertebrate nervous system (Barbosa-Morais et al. 2012;

(C) 2015 Quesnel-Vallières et al. This article is distributed exclusively by Cold Spring Harbor Laboratory Press for the first six months after the fullissue publication date (see http://genesdev.cshlp.org/site/misc/terms. xhtml). After six months, it is available under a Creative Commons License (Attribution-NonCommercial 4.0 International), as described at http://creativecommons.org/licenses/by-nc/4.0/. 
Merkin et al. 2012). Indeed, AS patterns are more complex in the brain than other tissues, and many of these events happen in genes implicated in complex neuronal processes, such as the control of synaptic plasticity associated with cognition (Lipscombe 2005; Ule and Darnell 2006). While most tissue differential splicing patterns are species-specific in vertebrates, there is a higher frequency of conserved alternative cassette exon inclusion events in vertebrate brains than in other tissue types (Barbosa-Morais et al. 2012; Merkin et al. 2012). This suggests the existence of a core set of conserved functions for AS across vertebrate species in addition to roles for AS underlying species-specific neurodevelopmental and behavioral characteristics. However, little is known about the in vivo functions of the protein factors that are responsible for establishing AS complexity in the nervous system or the functions of the individual AS events that are controlled by these factors.

Neural-enriched splicing regulators, including the Nova, Rbfox, and Ptbp proteins, have been characterized using mouse models. Nova proteins, which were originally identified as the autoantigens in patients with paraneoplastic opsoclonus myoclonus ataxia (Buckanovich et al. 1993; Yang et al. 1998), control the inhibitory synapse, and their knockout results in cortical migration (Yano et al. 2010) and neuromuscular junction (NMJ) defects (Ruggiu et al. 2009). Rbfox1 and Rbfox 2 mutant mice are susceptible to seizures and display disrupted cerebellar development (Gehman et al. 2012). Depending on the strain background, Ptbp2 knockout mice die at birth or else exhibit cortical degeneration and lethality during the first few postnatal weeks (Licatalosi et al. 2012; Li et al. 2014). Additional studies using Nova knockout mice have revealed functions for specific Nova-regulated splice variants (including alternative exons in the Dab1 gene) that facilitate the proper migration of newly born cortical neurons (Yano et al. 2010) and exons in the Agrin gene that are important for the formation of NMJs (Ruggiu et al. 2009). However, aside from these examples, few other neuronal genes have been characterized at isoform resolution in vivo (Norris and Calarco 2012; Lipscombe et al. 2013b; Zheng and Black 2013).

We previously identified and characterized the vertebrate- and neural-specific Ser/Arg repeat-related protein of $100 \mathrm{kDa}$ (nSR100/SRRM4) (Calarco et al. 2009; Raj et al. 2011, 2014). Knockdown and overexpression experiments performed in cell culture revealed that nSR100 promotes the inclusion of $30 \%-50 \%$ of the conserved human and mouse cassette alternative exons that display brainspecific inclusion patterns in transcriptome profiling data (Raj et al. 2014). Knockdown of nSR100 in Neuro2a cells and developing zebrafish was shown to impair neurite outgrowth and branching of trigeminal ganglia, respectively (Calarco et al. 2009), and in utero knockdown of nSR100 in mice prevented differentiation of neuronal progenitors in the cortex (Raj et al. 2011). Recently, the Bronx waltzer $(b v)$ mouse mutation was mapped to the nSR100 gene (Nakano et al. 2012). bv homozygotes display hearing and balance defects attributed to degeneration of inner ear hair cells. The apparent limited pheno- typic consequences of the $b v$ mutation are likely because this mutation eliminates only the terminal exon and part of the $3^{\prime}$ untranslated region (UTR) of nSR100 transcripts, leaving the majority of the nSR100 protein intact.

nSR100-regulated exons were found to be concentrated in genes that function in various aspects of neuronal development and function (Calarco et al. 2009; Raj et al. 2011, 2014; Nakano et al. 2012). These and other neuralregulated exons that are $>27$ nucleotides (nt) in length are highly concentrated in surface-accessible disordered regions of proteins and function in the regulation of protein-protein interactions (Buljan et al. 2012; Ellis et al. 2012). Furthermore, in a very recent study, we showed that nSR100 strongly promotes the inclusion of very short, 3- to 27-nt, neuronal "microexons" (Irimia et al. 2014). The corresponding microexon residues are concentrated within-or immediately adjacent to-protein-protein or protein-lipid interaction domains. Most of these exons display striking increases in inclusion during neuronal maturation, coincident with increased expression of nSR100. Notably, they also show significant decreases in inclusion-coincident with reduced expression of nSR100 - in the cortices of individuals with autism spectrum disorder (ASD) (Irimia et al. 2014). A key function of nSR100 thus appears to be the widespread regulation of protein interactions required for the maturation and proper function of neurons. However, the scope of the in vivo functions of nSR100 during nervous system development has not been previously addressed.

To investigate the functions of nSR100 in vivo, we generated mice carrying a conditional exon deletion in the nSR100 (Srrm4) gene that results in widespread loss of the full-length protein. We observed that nSR100 is essential for early postnatal survival of a large majority of mutant animals, with the few surviving animals displaying balance defects similar to those seen in $b v / b v$ mice but also exhibiting persistent tremors. Additionally, loss of nSR100 in mice results in impaired neurite outgrowth in the diaphragm, early neuronal commitment of neural progenitors leading to defective cortical layering, and a failure of callosal axons to cross the midline in the forebrain. Using RNA sequencing (RNA-seq) profiling, we defined all classes of AS (including alternative microexons and longer alternative cassette exons, $5^{\prime}$ and $3^{\prime}$ splice sites, and retained introns) that are controlled by nSR100 in vivo, a great majority of which were not previously reported. A large fraction of alternative cassette exons and microexons positively regulated by nSR100 are neurally enriched, which is not the case for other classes of nSR100-dependent splicing events. Moreover, a higher proportion of neural microexons is affected by disruption of nSR100 than are other neural-regulated AS events. These include highly conserved exons with the potential to insert only one or two amino acids in proteins of key functional relevance to neuronal maturation. Remarkably, an nSR100regulated 6-nt microexon in the Unc13b gene promotes neurite growth in mouse primary neurons. Cortical neurons from $n S R 100^{\Delta 7-8 / \Delta 7-8}$ mice display a neuritogenesis defect, and expression of Unc13b transcripts including 
the microexon, but not transcripts lacking the microexon, is sufficient to rescue the mutant phenotype. Collectively, our results define critical new in vivo functions of nSR100 during mouse development and further link these functions to the disruption of a conserved program of nSR100-dependent neuronal microexons.

\section{Results}

\section{Perinatal mortality in nSR100 mutant mice}

Our previous studies using in vivo knockdown of nSR100 in zebrafish and mouse embryos suggested that nSR100 may play a role in several aspects of nervous system development (Calarco et al. 2009; Raj et al. 2011). To address the extent of nSR100 functions in the developing nervous system, we generated mice carrying a conditional knockout $n S R 100^{\text {Iox }}$ allele from embryonic stem cells obtained from EUCOMM (European Conditional Mouse Mutagenesis Program). The $n S R 100^{l o x}$ allele includes a gene trap upstream of a LacZ reporter and LoxP sites framing $n S R 100$ exons 7 and 8 (Fig. 1A). Southern blotting confirmed the integrity of the integration site in $n S R 100^{10 x}$ mice (Fig. 1B). We crossed $n S R 100^{+/ l o x}$ mice with mice carrying the widely expressed CMV-Cre recombinase transgene to obtain $n S R 100^{\Delta 7-8}$ mice, in which exons 7 and 8 have been deleted throughout the animal and in the germline. This deletion introduces a +2 frameshift in downstream exons and causes complete loss of full-length $\mathrm{nSR} 100$ transcripts and protein in homozygous $n S R 100^{\Delta 7-8}$ mice (Fig. 1C,D). Immunoblotting revealed that a $25-\mathrm{kDa}$ protein fragment could be detected in homozygous and heterozygous mutant mice using an antibody to the $\mathrm{N}$ terminus of nSR100. RT-PCR confirmed that transcripts encompassing $n S R 100$ exons $1-6$ and the gene trap insertion are preserved in the mutant mouse (Supplemental Fig. S1A). The small N-terminal fragment produced from the $n S R 100^{\Delta 7-8}$ allele lacks the RS-rich domain of nSR100 (Supplemental Fig. S1B), which, based on previous studies of nSR100 and other SR proteins, is predicted to function in the formation of protein-protein and/or protein-RNA interactions required for splicing complex formation (Wu and Maniatis 1993; Shen and Green 2004; Raj et al. 2014). In contrast to the full-length protein, overexpression of the truncated protein in Neuro2a cells depleted of endogenous nSR100 fails to restore nSR100-dependent splicing (Supplemental Fig. S1C, lanes 1-3). Moreover, when coexpressed with full-length nSR100 in Neuro2a cells, the truncated mutant does not interfere with splicing of nSR100 target exons (Supplemental Fig. S1C, lanes 4-6). These observations provide evidence that the $25-\mathrm{kDa}$ protein fragment lacks critical functional activities associated with full-length nSR 100 .

We observed that $>85 \%$ of $n S R 100^{\Delta 7-8 / \Delta 7-8}$ mice died in the first few hours after birth (Supplemental Table S1). Although these mice present no gross morphological phenotype at late embryonic stages or at birth (Fig. 1E), they show signs of respiratory defects, including irregular breathing and heavy gasping, and become cyanotic soon after birth. This phenotype contrasts sharply with those
A

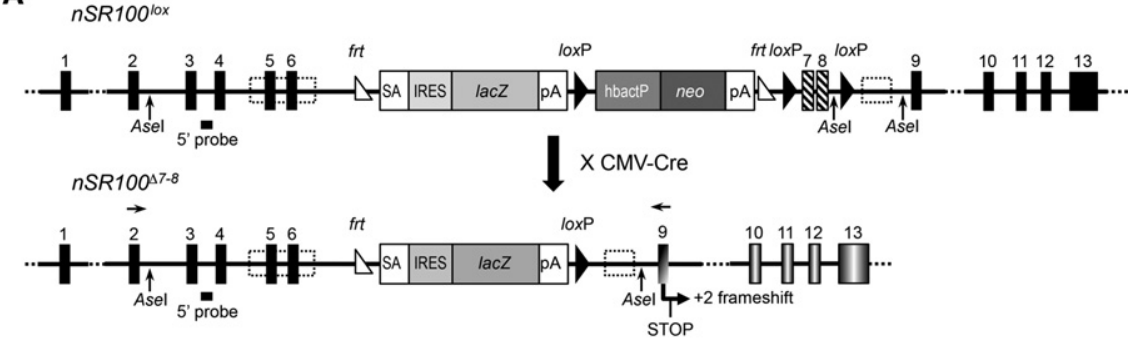

B

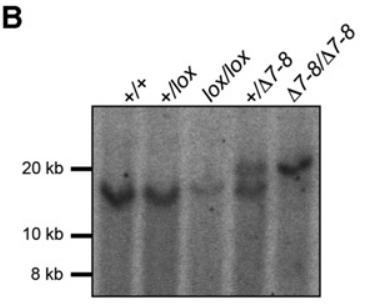

E

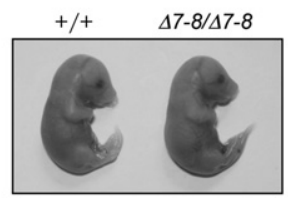

C

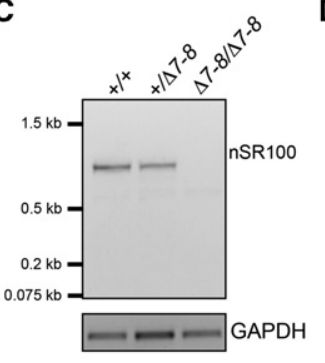

D

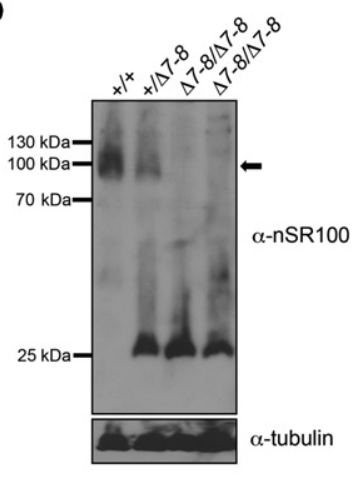

Figure 1. Loss of the full-length nSR100 protein in $n S R 100^{\Delta 7-8 / \Delta 7-8}$ mutant mice. (A, top panel) Map of the conditional nSR100/SRRM4 allele showing the positions of exons, Frt (open triangles) and LoxP (solid triangles) recombination sites, homology arms (dashed boxes), and cutting sites for the AseI restriction enzyme (vertical arrows) and the probe (solid bar) used for Southern blot analysis (see B). (Bottom panel) Map of the knockout allele following crossing of the conditional $n S R 100^{\text {Iox }}$ mouse with a CMV-Cre transgenic line. Cre-LoxP recombination drives the loss of $n S R 100$ exons 7 and 8 and results in $\mathrm{a}+2$ frameshift and the introduction of several premature termination codons downstream from the deletion. The position of primers used for RT-PCR (horizontal arrows; see $C)$ is indicated. Homozygous $n S R 100^{10 x / 10 x}$ mice do not display any overt phenotype. (B) Southern blot analysis on tail DNA from wild-type $(+/+)$, conditional (lox), and knockout $(\Delta 7-8)$ mice. DNA was digested with AseI and hybridized with a probe binding upstream of the $5^{\prime}$ homology arm on the conditional allele in intron 3. Predicted band size is $15.4 \mathrm{~kb}$ in wild-type, $16.4 \mathrm{~kb}$ in conditional, and $19.4 \mathrm{~kb}$ in knockout alleles, respectively. (C) RT-PCR on embryonic day 16.5 (E16.5) whole-brain total RNA using primers amplifying exon 2 to exon 9. No transcript could be detected in homozygous mutants. $(D)$ Immunoblotting on E17.5, whole-brain lysates using an antibody to nSR100. Full-length nSR100 protein is completely lost in homozygous mutants (arrow), but a 25 -kDa fragment is expressed from the $\Delta 7-8$ allele. $(E)$ E17.5 mutant embryos display normal morphology. 
of the previously described nSR100 mutant $b v$ mouse, in which only the last 103 amino acids from the $\mathrm{C}$ terminus of nSR100 are lost. Homozygous $b v$ mice are viable and display a phenotype limited to the degeneration of the inner hair cells of the inner ear (Deol and GluecksohnWaelsch 1979; Nakano et al. 2012). Notably, the few homozygous $n S R 100^{\Delta 7-8 / \Delta 7-8}$ survivors that we obtained from crossing heterozygous parents display a head tilting and circling behavior reminiscent of the balancing defect observed for the $b v$ mutant strain. However, in contrast to the $b v$ mutant, all surviving $n S R 100^{\Delta 7-8 / \Delta 7-8}$ individuals additionally display pronounced tremors, a phenotype that is often associated with neurobiological defects (Supplemental Videos S1-S3). Homozygous mutants escaping perinatal mortality did not display significant differences in life span compared with wild-type littermates (data not shown). Embryos harvested at embryonic day 17.5 (E17.5) and E18.5 were found at Mendelian ratios (Supplemental Table S1), indicating that loss of nSR100 does not cause early embryonic lethality. The extensive perinatal mortality and neurobiological phenotypes observed in surviving $n S R 100^{\Delta 7-8 / \Delta 7-8}$ mice highlight the importance of nSR100 during embryonic development as well as its role in the proper functioning of the adult nervous system.

\section{Loss of nSR100 impairs diverse neuronal processes}

The respiratory problems accompanying perinatal mortality in $n S R 100^{\Delta 7-8 / \Delta 7-8}$ mice suggested that the innervation of the diaphragm might be impaired by loss of the nSR100 protein. We first asked whether $n S R 100$ is expressed in the peripheral nervous system where motor neurons innervating the diaphragm are located. We surveyed nSR100 expression at different time points during development using both the LacZ cassette in the nSR $100^{\text {lox }}$ mouse as a reporter for $n S R 100$ gene expression and in situ RNA hybridization in wild-type mice. X-Gal staining and in situ hybridization showed that nSR100 is expressed in both the brain and the neural tube during early neurogenesis, with nSR100 mRNA expressed as early as E8.5 and LacZ reporter expression starting at E9.5 (Supplemental Figs. S2A,B, S3A). Immunostaining of sections from $n S R 100^{+/ l o x}$ mice using anti- $\beta$-galactosidase antibody and anti-NeuN antibody to mark post-mitotic neurons revealed that only neurons express nSR100 in the brain (Supplemental Fig. S3B). Moreover, in situ hybridization at E17.5 showed that nSR100 expression is maintained in the brain during development, with high expression in the cerebral cortex and hippocampus late in embryogenesis (Supplemental Fig. S2C). These results are consistent with recent analyses of RNA-seq data from diverse human and mouse cell and tissue types and a neuronal differentiation time series, which indicated that nSR100 expression is neuron-specific, occurs in the brain and dorsal root ganglia, and increases in the brain from E11 to E18 before decreasing in the adult (Irimia et al. 2014; Raj et al. 2014). Taken together, these data confirm that nSR100 is neuronal-specific and is expressed in both the central and peripheral nervous system in developing mice.

We next visualized the innervation of the diaphragm just before birth at E18.5 using an antibody to neurofilament on whole-mount preparations. This staining revealed that primary branches deriving from the phrenic nerve appear thinner in $n S R 100^{\Delta 7-8 / \Delta 7-8}$ mice (Fig. 2A). In addition, we observed that the total length covered by secondary motor axons is greatly reduced and that the number of secondary axons is decreased by almost twofold in homozygous mutants, a phenotype not seen in heterozygotes (Fig. 2B,C). These defects are already present at E16.5 (Supplemental Fig. S4A-C), suggesting that the lack of secondary branches does not stem from degeneration or pruning but rather from deficient sprouting in the mutant mice. The overall distance covered by primary axons was not affected at either E18.5 or E16.5 (Fig. 2D; Supplemental Fig. S4D). Each individual secondary branch forming in the mutants projects as far as its wild-type
A
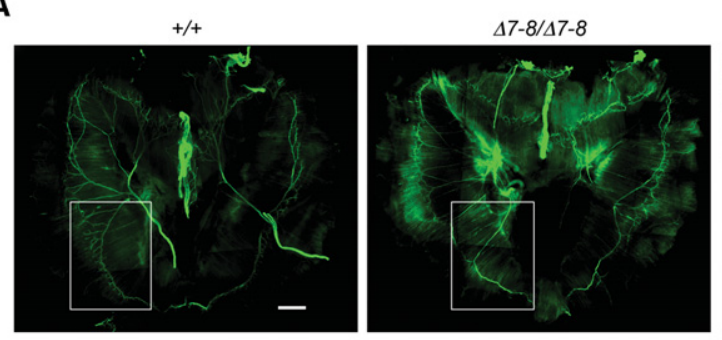

c

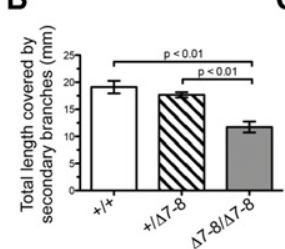

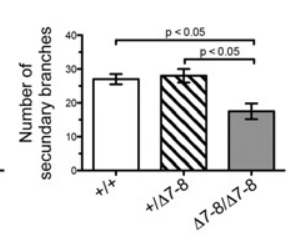

D

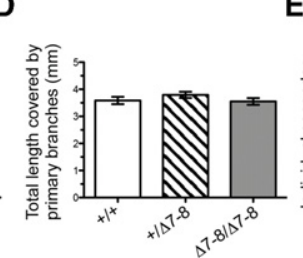

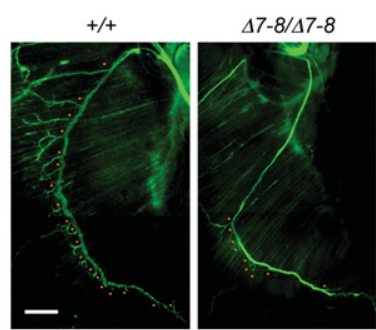

E

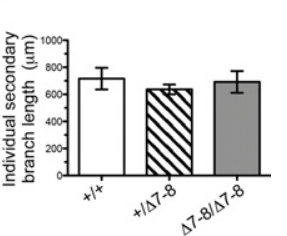

Figure 2. Loss of nSR100 impairs neurite outgrowth in motor neurons. $(A)$ Wholemount staining of E18.5 diaphragms with anti-neurofilament antibody (green) to highlight innervation. Orange dots mark secondary branches in the insets. Bars: left panels, $1000 \mu \mathrm{m}$; insets, $500 \mu \mathrm{m} .(B, C)$ The total distance covered by all secondary axons $(B)$ and the number of secondary branches present on the right ventral primary branch of the phrenic nerve $(C)$ were quantified on three or four individuals for each genotype. The total distance covered by secondary neurites and the number of secondary branches formed are significantly lower in homozygous mutants. $(D)$ The total length covered by primary branches is not affected in homozygous mutants. $(E)$ The average length of individual secondary branches in the mutant does not differ significantly from those of wild-type and heterozygous littermates. Three diaphragms from wild-type and heterozygous embryos and four diaphragms for homozygous mutants were analyzed. One-way ANOVA with Tukey-Kramer post-hoc test. Error bars indicate standard error of the mean. 
counterpart (Fig. 2E; Supplemental Fig. S4E), and motor endplates form in the same numbers in the diaphragm of nSR100 homozygous and heterozygous mutant mice, although at higher density in the homozygous mutant, most likely due to a lack of secondary branching (Supplemental Fig. S4F-H). The diminished axon sprouting capacities of motor neurons in the diaphragm of $n S R 100^{\Delta 7-8 / \Delta 7-8}$ mice likely contributes to nSR100-dependent respiratory defects and early postnatal death. These axon guiding or branching defects are not limited to phrenic nerve innervation, as we detected defective formation of the trigeminal, hypoglossal, and spinal nerves in whole-mount staining of E10.5 and E12.5 embryos (Supplemental Fig. S5).

Because nSR100 is highly expressed in the cortex and in utero knockdown of $n S R 100$ resulted in defects in neuronal differentiation in the cortex (Raj et al. 2011), we investigated whether cortical anatomy was altered in nSR100 mutants. The establishment of defined cortical layers is an important and conserved step in mammalian brain development. Immunofluorescence using layer-specific markers revealed that the deep, T-box brain 1 (Tbr1)-positive cortical layer VI is enlarged and comprised of more cells in the homozygous mutant, a phenotype also seen to a lesser extent in heterozygotes $(P<0.0001$, one-way ANOVA) (Fig. 3A,B). The definition of the preplate was also altered in homozygotes and heterozygotes. Costaining with antibodies to Tbr1 and Satb2 to highlight superficial layers II-V revealed a decrease in the number of superficial neurons in nSR100 mutants $(P<0.05$, oneway ANOVA) (Fig. 3A,C). The total number of post-mitotic neurons was also reduced in the mutants, as highlighted by NeuN staining $(P<0.0001$, one-way ANOVA) (Fig. 3A,D).

We postulated that the increase in the number of earlyborn neurons and decrease in the number of late-born neurons observed in nSR100 mutants may be due to the premature commitment of neural progenitors to a post-mitotic fate. Indeed, Pax6 staining at E18.5
A

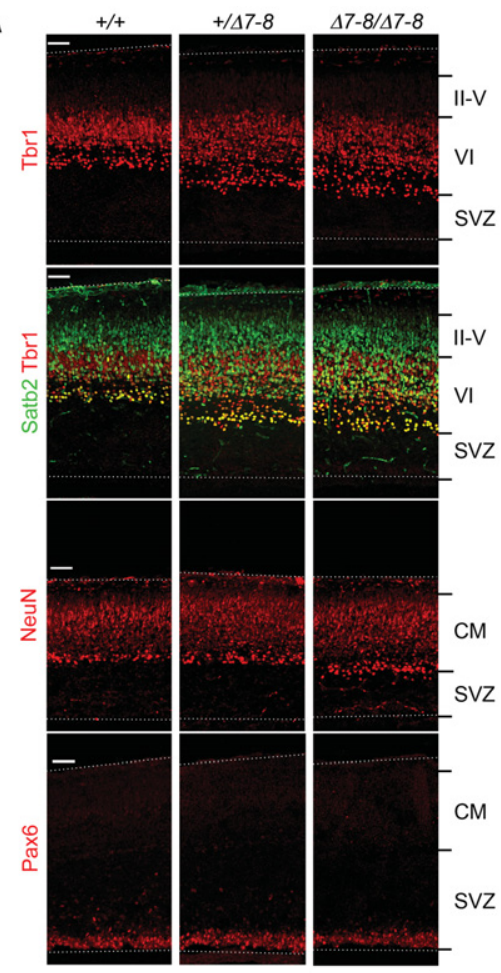

B

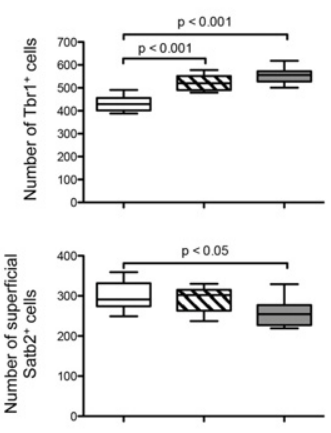

D

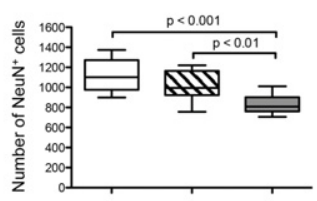

E

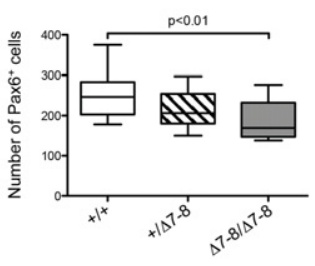

$\mathbf{F}$

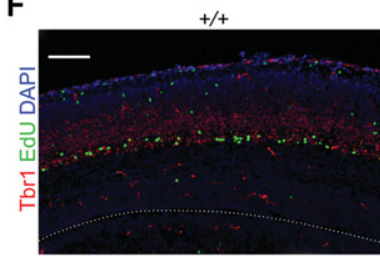

H

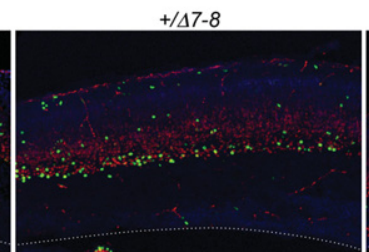

I

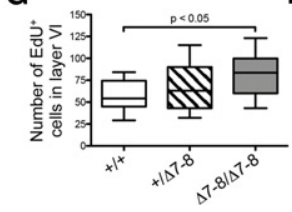

$\Delta 7-8 / \Delta 7-8$

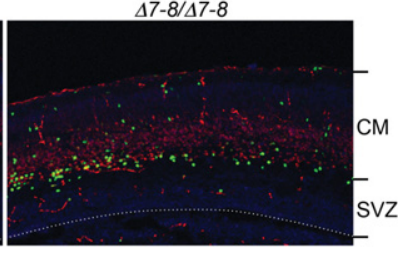

$J$

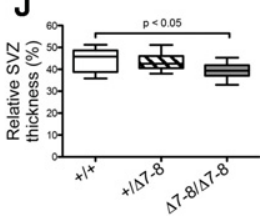

Figure 3. nSR100 mutant mice display aberrant cortical layering and premature neurogenesis. (A) Immunofluorescence microscopy using antibodies to Tbr1, Satb2, NeuN, and Pax6 to label deep layer VI, superficial layers II-V, post-mitotic neurons, and neural progenitors, respectively, on coronal sections of E18.5 embryonic brains. Bars, $50 \mu \mathrm{m}$. (I-VI) Cortical layers I-VI, (CM) cortical mantle. Dashed white lines highlight ventral and dorsal cortical boundaries. $(B-E)$ The number of $\operatorname{Tbr}^{+}(B)$, layer II-V Satb2 ${ }^{+}(C), \mathrm{NeuN}^{+}(D)$, and Pax6 $^{+}(E)$ cells was quantified for three to five individuals per genotype and on three sections for each individual. These immunostaining experiments highlight an increase in the number of deep, early-born $\mathrm{Tbrl}^{+}$neurons and a corresponding decrease in superficial Satb2 ${ }^{+}$neurons as well as a decrease in the total number of neurons $\left(\mathrm{NeuN}^{+}\right)$and neural progenitors $\left(\mathrm{Pax}^{+}\right) .(F)$ EdU-labeling was performed at E12.5 (green), and brains were harvested at E18.5 and stained with an antibody to Tbrl (red). Bar, $100 \mu \mathrm{m}$. $(G-I)$ The number of EdU ${ }^{+}$cells was counted in deep layer VI $(G)$, superficial layers II-V $(H)$, and the SVZ $(I)$. (J) The thickness of the SVZ was measured from the preplate to the lateral ventricle and relative to the total thickness of the cortex measured from the surface of layer I to the lateral ventricle. Four to five embryos per genotype and three sections per embryo were analyzed. Whiskers indicate the 10th and 90th percentiles in all box plots. One-way ANOVA with Tukey-Kramer post-hoc test. 
confirmed that the pool of neural progenitors is depleted in $n S R 100^{\Delta 7-8 / \Delta 7-8}$ mice at the end of embryogenesis $(P<0.05$, one-way ANOVA) (Fig. 3A,E). To verify whether deregulation of neurogenesis was the major cause for the cortical layering phenotype, we performed 5-ethynyl-2'deoxyuridine (EdU) labeling at E12.5, when early neurons populating deep cortical layers are born, and harvested the labeled brains at E18.5. Costaining for $\mathrm{EdU}^{+}$and $\mathrm{Tbr}^{+}$ cells confirmed that a greater number of $\mathrm{Tbr}^{+}$cells are born at E12.5 in nSR100 mutants $(P<0.05$, one-way ANOVA) (Fig. 3F,G). The increase in the number of $\mathrm{EdU}^{+}$cells was specific to the deep cortical layer VI, as a similar number of EdU ${ }^{+}$cells was observed in the SVZ and superficial cortical layers across all genotypes (Fig. $3 \mathrm{H}, \mathrm{I})$. Finally, we detected an overall thinning of the SVZ in nSR 100 mutant brains $(P<0.05$, one-way ANOVA) (Fig. 3J) that parallels the early post-mitotic commitment of progenitors and the reduction of their numbers. Taken together, these results indicate that the cortical layering defects in $n S R 100^{\Delta 7-8}$ mice are primarily caused by deregulation of the timing of early neurogenesis.

Interestingly, while analyzing cortical layering, we noticed that the morphology of the rostral part of the corpus callosum in $n S R 100^{\Delta 7-8 / \Delta 7-8}$ mice differed from its stereotypical shape. The corpus callosum consists mostly of cortical axons crossing the midline to contact neurons of the opposite hemisphere. This interconnection between hemispheres is essential for the fast processing of information and cognition (Paul et al. 2007). Neurofilament immunostaining revealed that several callosal axons are misguided in the absence of nSR100 and form thick ectopic fascicles similar to Probst bundles, projecting ventrally instead of crossing the midline (Fig. 4A). This phenotype is never observed in wild-type mice but is important enough in homozygous mutants to alter the shape of the corpus callosum. Although the corpus callosum of $n S R 100^{+/ \Delta 7-8}$ mice does not appear grossly misshapen, it also contains ectopic ventrally projecting bundles (Fig. 4B). These observations represent the first example of a midline crossing defect as a consequence of the knockout of an AS regulator. Overall, our phenotypic survey so far shows that nSR 100 controls a diverse array of neuronal functions in both the central and peripheral nervous systems, including cortical layering, axon guidance, and midline crossing.

\section{An in vivo nSR100-regulated splicing program}

To identify AS events that contribute to the aforementioned neurodevelopmental deficits, we performed RNA-seq analyses on two sets of biological replicate samples, each consisting of pooled E18.5 mouse cortical or hippocampal tissue from wild-type and $n S R 100^{\Delta 7-8 / \Delta 7-8}$ mice (eight samples in total). An RNA-seq analysis pipeline was employed that generates quantitative estimates for "percent spliced in" (PSI) values for alternative cassette exons, "percent splice site usage" (PSU) values for sequences formed by alternative $5^{\prime} / 3^{\prime}$ splice site selection, and "percent intron retained" (PIR) values for intron retention events (Braunschweig et al. 2014; Irimia et al. 2014). This pipeline also identifies and quantifies PSI values for 3- to 27-nt microexons (Irimia et al. 2014). To identify which AS events were differentially spliced between wild-type and $n S R 100^{\Delta 7-8 / \Delta 7-8}$ brains, we performed a paired $t$-test between the four pairs of samples and required an average $\triangle \mathrm{PSI} / \mathrm{PIR} / \mathrm{PSU}$ between pairs of samples of $\geq 10$. Of the 263 AS events displaying differential splicing according to these criteria (Supplemental Table S2), cassette alternative exons, including microexons, represented the largest class, comprising $58 \%$ of the total (Fig. 5A). A large number of retained introns as well as a few alternative $3^{\prime}$ and $5^{\prime}$ alternative splice sites were also misregulated in $n S R 100^{\Delta 7-8 / \Delta 7-8}$ brain tissues. Of the alternative cassette exons and microexons that displayed changes, $66(83 \%)$ and $72(100 \%)$, respectively, displayed decreased PSI levels in $n S R 100^{\Delta 7-8 / \Delta 7-8}$ mouse brains. Furthermore, $70 \%$ of cassette and $96 \%$ of microexons positively regulated by nSR100 were defined by RNA-seq profiling of multiple wild-type mouse tissues (Irimia et al. 2014) as having increased neural inclusion compared with other tissues (Fig. 5B). Other classes of AS events displaying differential splicing in $n S R 100^{\Delta 7-8 / \Delta 7-8}$ mice did not display enrichment for neural-specific regulation or nSR100-dependent inclusion.

An analysis of the cumulative distributions of exon lengths for cassette exons shows that nSR100-regulated exons are significantly shorter than the full set of neurally regulated exons with either increased or decreased neural PSI as well as nonneural alternative exons $\left(P<10^{-7}\right.$ for all comparisons with nSR100-regulated exons; Wilcoxon rank-sum tests) (Fig. 5C). Moreover, consistent with our
A

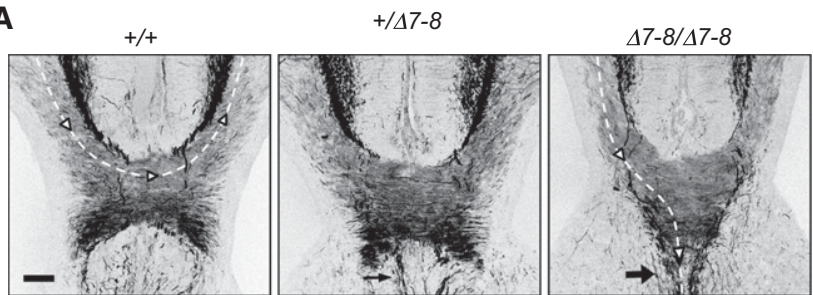

B

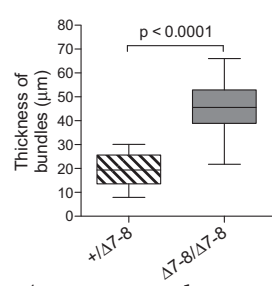

Figure 4. Midline crossing defects in nSR100 mutant mice. (A) Negative grayscale images of immunofluorescence microscopy using an antibody to neurofilament on coronal sections of the rostral part of the corpus callosum of E18.5 embryos. Dashed lines with arrowheads show either the prototypical tracts of callosal axons in the wild-type $(+/+)$ or the ectopic ventral projections in the homozygous mutant $(\Delta 7-8 / \Delta 7-8)$. Arrows indicate ectopic bundles in the heterozygous and homozygous mutants. Bar, $100 \mu \mathrm{m}$. (B) The thickness of ventrally projecting bundles was measured at three levels on each side of the corpus callosum for three $(+/ \Delta 7-8)$ or four $(\Delta 7-8 / \Delta 7-8)$ individuals per genotype and on three sections for each individual. Whiskers indicate the 10th and 90th percentiles. One-tailed Mann-Whitney test. 
A

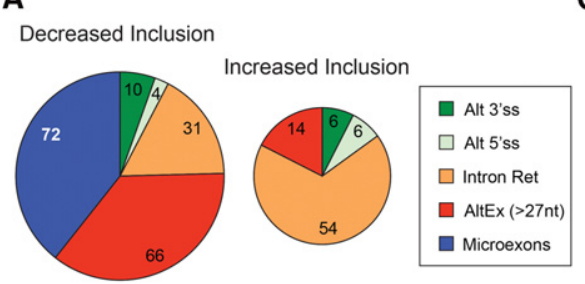

B

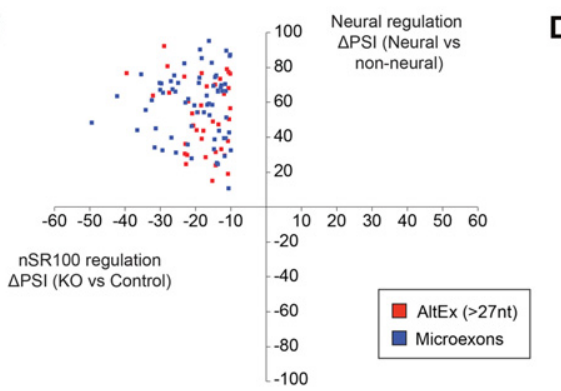

C

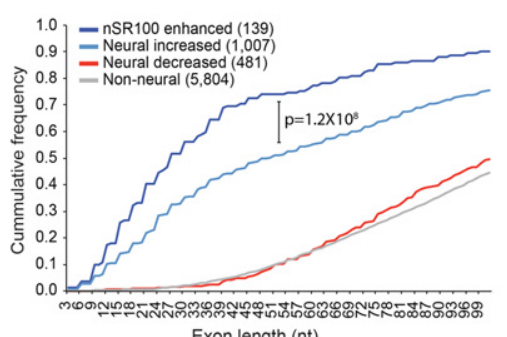

D

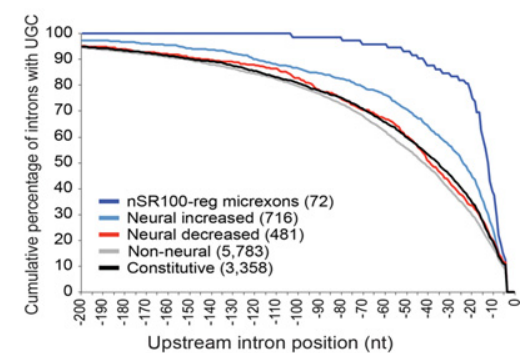

E

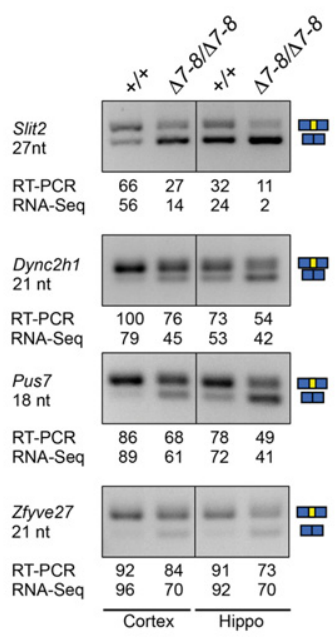

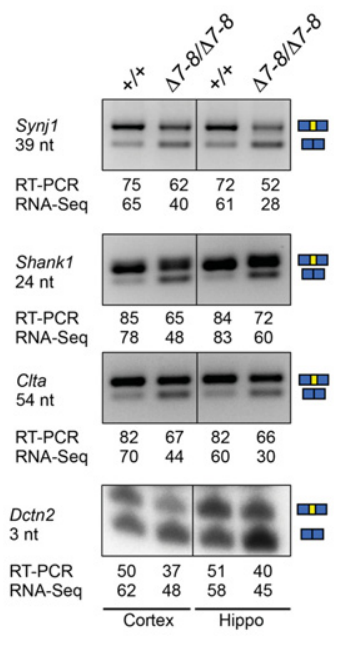

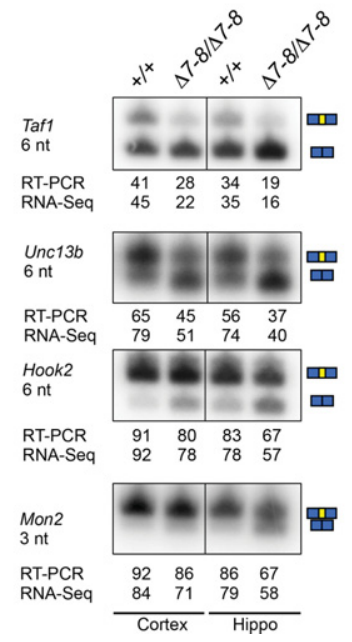

Figure 5. nSR100 regulatory program in the mouse brain. (A) Number of AS events showing significantly decreased (left) or increased (right) inclusion upon nSR100 deletion in mouse brains, plotted by class. (AltEx) Alternative cassette exons. (B) Microexons (blue) and longer cassette exons (red) were plotted based on their PSI difference between $n S R 100^{\Delta 7-8 / \Delta 7-8}$ and wildtype samples ( $X$-axis) and their $\Delta$ PSI between the average of neural versus nonneural tissues ( $Y$-axis) as previously determined (Irimia et al. 2014). (C) Cumulative distribution of exon lengths for different groups of alternative exons, including events that show decreased inclusion in $n S R 100^{\Delta 7-8 /}$ ${ }^{\Delta 7-8}$ compared with the control (nSR100-enhanced; dark blue), all alternative exons with increased neural PSI /neural increased; light blue), all alternative exons with decreased neural PSI (neural decreased; red), and nonneural alternative exons (nonneural; gray). (D) Cumulative distribution plots indicating the position of the first UGC motif within 200 nt upstream of nSR100-regulated microexons (dark blue), longer exons (>27 nt) with increased neural inclusion (light blue), exons with decreased neural inclusion (red), and nonneural (gray) and constitutive (black) exons. The number of exons used in the analysis for each subgroup is indicated in parentheses. (E) RT-PCR validations of nSR100-regulated cassette exons in cortical (left two lanes) and hippocampal (right two lanes) samples. PSI values calculated from semiquantitative RT-PCR or RNA-seq analysis are shown below the gel for each event. Cassette exon included isoforms are represented by yellow boxes flanked by blue constitutive exons. Primers were located in flanking constitutive exons. recent results from analyzing nSR100-dependent, neuralregulated exons in cell lines (Raj et al. 2014), nSR100-regulated microexons show very strong enrichment for UGC motifs in the first several nucleotides upstream of microexons regulated by nSR100 in vivo (Fig. 5D). Of 22 analyzed differential splicing events involving alternative cassette and microexons, which were detected by RNAseq to undergo reduced inclusion as a consequence of the loss of nSR100, all were validated by semiquantitative RT-PCR assays, including 3- and 6-nt microexons (Fig. 5E; Supplemental Fig. S6). Expression analysis based on cRPKMs (corrected reads per kilobase per million mapped reads) revealed only nine genes, other than nSR100, with an average mRNA expression difference of $\geq 1.5$-fold between both replicates of wild-type and $n S R 100^{\Delta 7-8 / \Delta 7-8}$ tissues and $P<0.05$ (paired $t$-test) (Supplemental Table S3). Analysis of genes with alternative cassette exons and microexons affected by loss of nSR100 revealed significant enrichment $(P<0.01)$ for gene ontology $(\mathrm{GO})$ terms essential to many aspects of neuronal cell biology, such as "vesicle-mediated transport," "neurotransmitter secretion," "synaptosome," and "cell projection morphogenesis" (Supplemental Fig. S7). Collectively, these observations suggest that multiple neural cassette exons -in particular, highly conserved microexons that display marked decreases in inclusion levels as a consequence of the loss of nSR100-may underlie mutant phenotypes detected in nSR $100^{\Delta 7-8 / \Delta 7-8}$ mice.

\section{Functions of nSR100-regulated microexons}

Based on our previous and present analyses of the in vivo mutant phenotypes of zebrafish and mice lacking nSR100 and also the known functions of genes that harbor nSR100-dependent exons, a major function of the nSR100-regulated splicing program is likely to control different aspects of neurite outgrowth. Consistent with this proposal, we found that hippocampal neurons cultured from $n S R 100^{\Delta 7-8 / \Delta 7-8}$ mice have significantly shorter neurites compared with neurons from wild-type animals 
$(P<0.0001$, two-tailed Mann-Whitney test) (Fig. 6A,B). To investigate whether nSR100-regulated microexons may be responsible for neurite outgrowth, we focused on a previously uncharacterized, highly conserved nSR100 target microexon of $6 \mathrm{nt}$ in Unc13b/Munc13 (Fig. 5E), a gene that has previously been shown to contribute to early neuritogenesis in primary mouse neurons (Broeke et al. 2010). Since our RNA-seq analysis can only locate this microexon in the context of its immediate flanking constitutive exons due to short read length, Sanger sequencing of RTPCR products from mouse brains was performed. This revealed that the Unc13b microexon, located between exons 13 and 14, is spliced in transcripts that contain at least exons 5-14 and exons 11-20.

To address whether increased skipping of the Unc13b microexon may contribute to the neuritogenesis defect in $n S R 100^{\Delta 7-8 / \Delta 7-8}$ neurons, we harvested cortical neurons from wild-type and mutant E18.5 embryos, transfected them with red fluorescence protein (RFP)-Unc13b expression constructs that either include (Unc13b-inc) or skip (Unc13b-skp) the microexon (Fig. 6C,D), and plated them at low density. At day 2 in vitro (DIV2), the cellular distribution and expression levels of Unc13b-inc-RFP and Unc13b-skp-RFP appear similar (Fig. 6D,E; Supplemental Fig. S8A). Both Unc13b isoforms are distributed over the entire length of the axons, thereby facilitating the visualization of transfected neurons and quantification of individual neurites. Control RFP-expressing mutant cortical neurons display the same neuritogenesis defect as hippocampal neurons $(P<0.001$, Kruskal-Wallis test) (Fig. 6F). Remarkably, wild-type neurons expressing Unc13b-skpRFP produce neurites that are as short as mutant neurons expressing control RFP and significantly shorter than control wild-type neurons ( $P<0.05$, Kruskal-Wallis test) (Fig. $6 \mathrm{E}, \mathrm{F})$. Expression of the skipped Unc13b isoform does not further affect neurite growth in mutant neurons. Strikingly, however, while expression of Unc13-inc-RFP does not affect neurite growth in wild-type neurons, inclusion of the microexon in mutant cells restores the lengths of neurites to levels observed in wild-type neurons (Fig. 6E,F). Transfection of an nSR100-RFP expression vector in mutant neurons also results in longer neurites than in
A
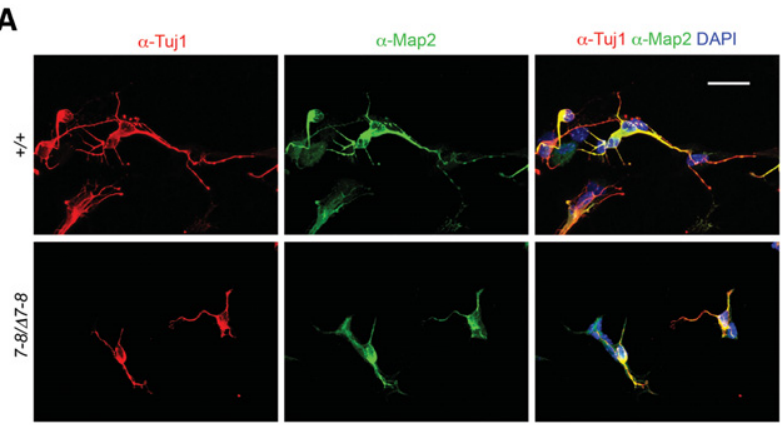

B

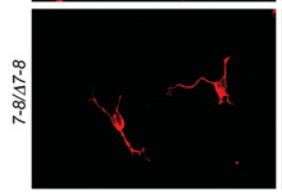

C

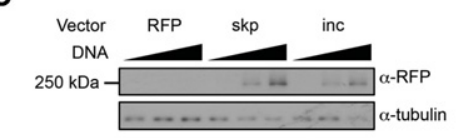

D

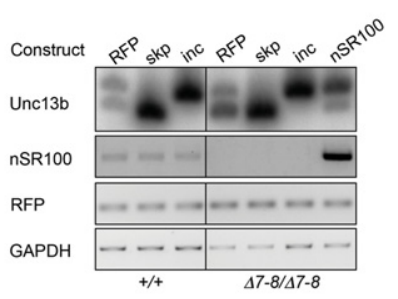

$\mathbf{F}$

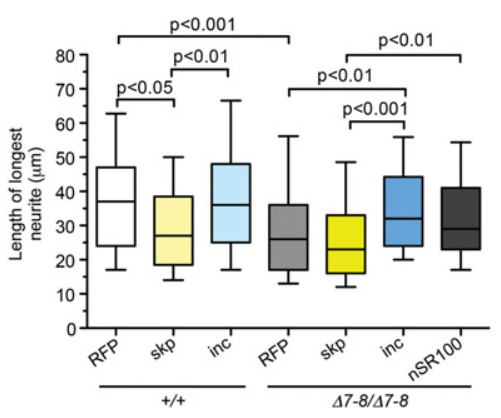

$\mathbf{E}$

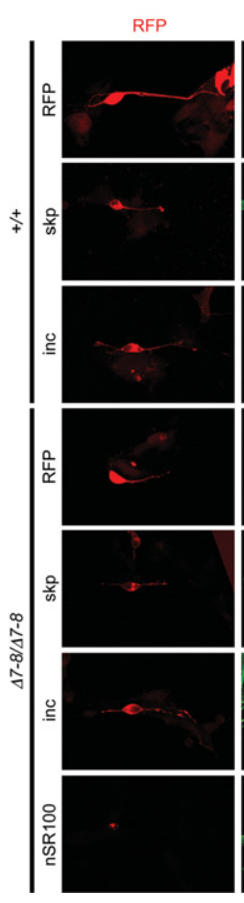

$\alpha-T u j 1$

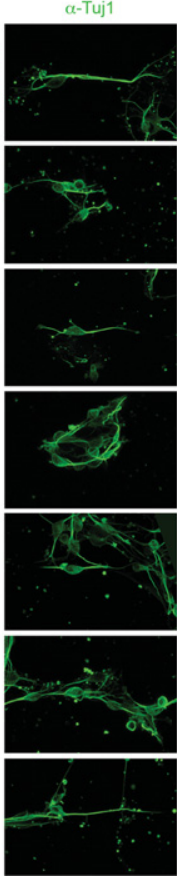

RFP $\alpha$-Tuj 1 DAPI

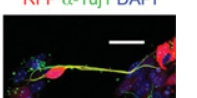

Figure 6. Functional regulation of a neural microexon by nSR100. (A) Representative images of primary hippocampal neurons from wild-type $(+/+)$ and $n S R 100^{\Delta 7-8 / \Delta 7-8}$ mice cultured for $2 \mathrm{~d}$ and then stained with antibodies to Tuj1 (red) and Map2 (green). Bar, $25 \mu \mathrm{m}$. (B) The length of the longest neurite was measured for each neuron. Four-hundred-fifty-one cells from wildtype embryos and 425 cells from mutant embryos were analyzed. (C) Immunoblotting with an antibody to red fluorescence protein (RFP) on Neuro2A lysates transfected with increasing amounts of the same constructs that were used for the experiments in $D-F$ showing Unc13b-skp-RFP (skp) and Unc13b-inc-RFP (inc) protein expression. (D) RT-PCR showing inclusion levels of the Unc13b microexon as well as RFP, nSR100, and GAPDH expression in transfected $n S R 100^{+/+}$and $n S R 100^{\Delta 7-8 / \Delta 7-8}$ cortical neuronal cultures. $(E)$ Representative images of primary cortical neurons from $n S R 100^{+/+}$and $n S R 100^{\Delta 7-8 / \Delta 7-8}$ mice transfected with RFP, Unc13b-skp-RFP (skp), Unc13b-inc-RFP (inc), or nSR100RFP; cultured for $2 \mathrm{~d}$; and then stained with an antibody to Tuj1 (green). nSR100RFP displays nuclear localization, as expected. Bar, $25 \mu \mathrm{m}$. $(F) n S R 100^{+/+}$primary cortical neurons were transfected with RFP, Unc13b-skp-RFP, or Unc13b-inc-RFP (three left groups), and $n S R 100^{\Delta 7-8 / \Delta 7-8}$ primary cortical neurons were transfected with the same constructs and nSR100RFP (four right groups). The longest neurites were measured in RFP-expressing cells. Whiskers indicate the 10th and 90th percentiles. Kruskal-Wallis test with Dunn's multiple comparison tests. 
mutant cells expressing Unc13b-skp-RFP $(P<0.05$, Kruskal-Wallis test) (Fig. 6E,F). Furthermore, it is noteworthy that untransfected wild-type neurons cultured in parallel with neurons transfected with any construct produced neurites of similar length, whereas shorter neurites were consistently detected in untransfected $n S R 100^{\Delta 7-8 / \Delta 7-8}$ neurons $(P<0.0001$, one-way ANOVA) (Supplemental Fig. S8B). This confirms that the differences in neurite length observed here are dependent on the specific construct that is expressed and are not a consequence of variability between cultures. These results thus reveal that the inclusion of a single nSR100-dependent microexon of $6 \mathrm{nt}$ can positively stimulate neurite formation and rescue a neurite growth defect in primary $n S R 100^{\Delta 7-8 / \Delta 7-8}$ neurons. The phenotypes that we observed in $n S R 100^{\Delta 7-8}$ ${ }^{1 \Delta 7-8}$ mice may therefore be attributed, at least in part, to the reduced inclusion of neuronal microexons.

\section{Discussion}

In this study, we generated and characterized mice deficient of $n S R 100 / S R R M 4$, a vertebrate- and neural-specific splicing factor that regulates $\sim 30 \%$ of alternative exons with increased neural inclusion, including a large number of highly conserved 3- to 27-nt microexons. We showed that the loss of nSR100 protein in vivo results in numerous neurodevelopmental defects during mouse embryogenesis that lead to early postnatal mortality in the majority of animals. We further linked these neurodevelopmental deficiencies to the loss of microexon regulation.

\section{nSR100 regulates multiple neurodevelopmental processes}

Some of the neurodevelopmental phenotypes observed in mice deficient of nSR100 may relate to altered phenotypes seen in other splicing factor knockouts, while others are unique. Neonatal lethality has been reported as a consequence of loss of the splicing regulator Ptbp2. Ptbp2 is expressed in neurons as well as in skeletal and cardiac muscle (Licatalosi et al. 2012), and mice lacking Ptbp2 are paralyzed at birth (Licatalosi et al. 2012; Li et al. 2014). However, mice lacking Ptbp2 specifically in neurons (Ptbp2 Nestin knockout mice) die within an hour of birth, similar to nSR100 mutants, and initiate breathing at a greatly reduced rate (Li et al. 2014). Given that nSR100 promotes the expression of Ptbp2 by activating the inclusion of an alternative exon that prevents nonsense-mediated decay of Ptbp2 transcripts (see above; Calarco et al. 2009), it is possible that the requirement for nSR100 for innervation of the diaphragm may relate, at least in part, to Ptbp2 misregulation. However, we found that only $32.8 \%$ of in vivo nSR 100 -regulated exons overlap with in vivo Ptbp2 targets. Therefore, overlapping and distinct exons targeted by these factors may contribute to breathing defects, paralysis, and early postnatal death. This conclusion is further supported by the obser- vation of phenotypes that are unique to $n S R 100^{\Delta 7-8 / \Delta 7-8}$ mice.

In addition, as in the case of $n S R 100^{\Delta 7-8 / \Delta 7-8}$ and Ptbp2 knockout mice, mice deficient in both Nova1 and Nova2 proteins (Nova double-knockout mice) showed respiratory defects at birth (Ruggiu et al. 2009). While phrenic nerve branching appeared normal, NMJs in E18.5 Nova double-knockout mice had few acetylcholine receptors (AChRs) and only rarely contacted motor axon terminals. In contrast, in $n S R 100^{\Delta 7-8 / \Delta 7-8}$ mice, motor endplates (sarcolemma folds in which AChRs concentrate) are of an abundance similar to those of $n S R 100^{+/ \Delta 7-8}$ heterozygous littermates, which are fully viable. However, the distribution of AChRs is altered due to the phrenic nerve deficits, which may be a consequence of altered axon branching and/or growth. While it is not clear why a small number of homozygous mutant mice are capable of surviving into adulthood, it is possible that partial and variable reductions in the levels of nSR100 target AS events may afford sufficient degrees of diaphragm innervation in some individuals. It is also known that inconsistent breathing can be regularized by an entrainment contribution from the respiratory center in the brainstem /Champagnat et al. 2011; Giraudin et al. 2012; Mellen and Thoby-Brisson 2012). It is therefore possible that sufficient entrainment may occur early enough in a small fraction of the homozygous mutants to allow for their survival. In any case, to our knowledge, the deficit in phrenic nerve branching in nSR100 mutants has not been described previously in mice deficient of other splicing regulators.

Another neurodevelopmental aberration in $n S R 100^{\Delta 7-8 / \Delta 7-8}$ mice that has not been previously observed in other splicing factor knockouts is the axon midline crossing defect in the corpus callosum. Approximately 60 mouse genes are known to be required for the formation of the corpus callosum (Paul et al. 2007; Donahoo and Richards 2009). Interestingly, our RNA-seq analysis revealed that transcripts from one of these genes, Slit2, contain one of the most strongly nSR100-dependent exons. Slit2 is secreted by distinct cell populations located at or near the midline. It binds Robo receptors expressed in growing axons to help mediate midline crossing. Its function has been extensively studied in vivo (Chedotal 2007), and a Slit2 knockout mouse displays a midline crossing defect that is strikingly similar to the one that we observed in $n S R 100^{\Delta 7-8 / \Delta 7-8}$ mice, with bundles of callosal axons projecting ventrally along the midline (Unni et al. 2012). The nSR100-dependent Slit2 microexon adds nine amino acids to the fifth EGF domain in the secreted N-terminal portion of the protein that is responsible for its repulsive activity during axon guidance. The differential activities of the resulting Slit2 isoforms have not been previously investigated, although an AS event in Robo3 that switches the axonal response to Slit proteins from attraction to repulsion has been reported (Chen et al. 2008). It is interesting to consider that the nSR100-dependent regulation of the alternative Slit2 exon represents a complementary mechanism for controlling axon guidance and may contribute to the midline crossing defect observed in nSR100 mutant mice. However, because the loss of 
nSR100 also affects axon growth and the number and distribution of neurons that project callosal axons, we cannot exclude the possibility that a combination of these mechanisms may contribute to this anomaly.

In addition to the differences observed in the corpus callosum of nSR100 heterozygotes and homozygotes, we discovered nSR100 dosage-dependent cortical deficits. It is noteworthy that subtle deficits in the corpus callosum and cortical layering have been linked to impaired cognitive and behavioral function in humans (Paul et al. 2007). For example, disruption of cortical layer formation has been observed in individuals with schizophrenia and autism (Akbarian et al. 1993; Ross et al. 2006; Stoner et al. 2014). While cell migration defects often result in the aberrant positioning of cortical layers (Caviness 1982; Kwan et al. 2008), early production of post-mitotic neurons by cortical progenitors has been shown to result in an expansion of deep cortical layers (Feng and Walsh 2004). Premature production of neurons depletes the pool of progenitors and results in fewer late-born neurons being generated. In $n S R 100^{\Delta 7-8 / \Delta 7-8}$ mice, we found that layer VI is significantly expanded in mutant brains at E18.5, whereas the total number of neurons (including the number of superficial neurons) and neural progenitors is decreased. These phenotypes suggest that loss of nSR100 causes neural progenitors to fail to accomplish asymmetric division early during brain development and commit prematurely to a post-mitotic fate. Further supporting this proposal is our finding that more neurons are produced during the first steps of cortical development when nSR100 is lost. Finally, although the preplate was poorly defined in the brains of mutant mice, our fate-mapping experiments provide evidence that early-born, nSR100-depleted neurons migrate correctly to populate deep cortical layers. These observations thus establish nSR100 as an important regulator of neurogenesis timing.

\section{nSR100 regulates AS events in genes with important neuronal functions}

Our previous studies directed at the identification of nSR100 targets in cell lines focused on cassette alternative exons and revealed that nSR100 predominantly promotes neural exon inclusion (Calarco et al. 2009; Raj et al. 2011; Irimia et al. 2014). The RNA-seq analyses performed here confirmed this property of nSR100 and further encompassed a comprehensive survey of all classes of nSR100-regulated AS events detected in vivo. Notably, 65 of the 138 (47\%) (longer) cassette exons and microexons that are promoted by nSR 100 in vivo had not previously been reported as nSR 100 targets. Many of these events occur in genes with essential roles in neuronal biology and/or nervous system development (e.g., Ahi1, Camk2b, Dv11, Itsn1, Shank1, and Unc13b). Moreover, in addition to changes in the inclusion levels of a large number of neural cassette exons, of which many are microexons (see below), the present work also revealed that the nSR100 regulatory program extends to all classes of AS events. For example, many retained introns are misregulated in developing $n S R 100^{\Delta 7-8 / \Delta 7-8}$ mouse brains. Although a subset of the retained introns introduce premature termination codons, it appears that in most cases, the corresponding transcripts are not subject to nonsense-mediated mRNA decay, as their steady-state levels were not appreciably affected in $n S R 100^{\Delta 7-8 / \Delta 7-8}$ brain tissue (data not shown). We also identified a small number of nSR100-dependent alternative $5^{\prime}$ and $3^{\prime}$ splice site selection events, most of which are frame-preserving.

Collectively, AS events misregulated in $n S R 100^{\Delta 7-8 / \Delta 7-8}$ mouse brains are enriched in genes involved in neuronal functions, such as genes associated with neuronal differentiation (Zmynd8 and Ahi1), neurite outgrowth (Zfyve27 and Clasp2), and axon guidance (Slit2, Nrcam, and Mycbp2). Many of these genes possess pivotal roles as scaffolding proteins for endocytosis, exocytosis, cytoskeleton remodeling, and vesicle transport and are associated with defects similar to the ones that we observed in our mouse model.

\section{Functional impact of nSR100-regulated microexons}

Among genes that contain microexons regulated by nSR100, several encode proteins that are known to interact. These proteins form a network that is involved in the trafficking and recycling of vesicles, including Itsn1, Ppfia2, Rims2, Dnm2, Nbea, Abi1, Ptprd, and Vav2. Strikingly, 65 of the 72 nSR100-activated microexons are frame-preserving and have the potential to result in the insertion of one to nine amino acid residues in the corresponding protein products. These seemingly modest changes to coding sequence raise interesting questions as to the functional roles of microexons.

Recently, we and others have observed that amino acid residues encoded by microexons are almost invariably surface-accessible and enriched within—or immediately adjacent to-domains involved in protein-protein or protein-lipid interactions (Irimia et al. 2014; Li et al. 2015). Consistent with these observations, deletion of microexons reduces interactions with partner proteins. For example, a microexon in the SH3 domain of the Down syndrome-associated gene Itsn1, which we show here is strongly regulated by nSR100 (Supplemental Fig. S5), promotes interactions with multiple partners (Tsyba et al. 2008). A recent report demonstrated that an nSR100-regulated microexon in the Zfyve27 transcript (Fig. 5E) promotes interactions with partner proteins VAP-A and VAP-B (Ohnishi et al. 2014). Furthermore, we showed recently that neural microexons in the AP1 endocytic transport complex subunit Ap1s2 and the amyloid $\beta$ precursor protein-binding family B member 1 (Apbb1), which is also associated with neuritogenesis (Cheung et al. 2014), promote interactions with their respective partner proteins (Irimia et al. 2014). In the present study, we extend these findings by demonstrating that nSR100-dependent inclusion of a 6-nt microexon in Unc13b transcripts is sufficient to promote the increased length of neurites and rescue a neuritogenesis defect in nSR100 mutant neurons. This microexon has the potential to add two amino acids adjacent to a predicted MAPK-docking site in the Unc13b protein. It is therefore interesting to consider that the 
nSR100-dependent regulation of this microexon affects the phosphorylation status of Unc13b in ways that alter interactions required for neurite formation.

Finally, it is intriguing to note that most $(\sim 76 \%)$ of the microexons affected by the in vivo loss of nSR 100 in the present study are conserved in humans, and many $(\sim 46 \%)$ of these display loss of inclusion in the brain cortices of subjects with ASD (Irimia et al. 2014). Furthermore, this altered pattern of inclusion in ASD subjects affects genes enriched in known genetic associations with ASD and is also highly correlated with reduced expression of nSR100 (Irimia et al. 2014). Additional studies have linked microexon misregulation to schizophrenia and epilepsy (Ovadia and Shifman 2011; Rusconi et al. 2014). In the future, it will be of considerable interest to address whether partial alteration of nSR100 levels in developing mice may contribute to phenotypes associated with human neurological disorders.

\section{Materials and methods}

\section{nSR100 mutant mouse generation}

Stem cells containing the conditional nSR $100^{\text {lox }}$ allele were obtained from EUCOMM (project no. 71507, clones EPD0538_3_A08 and EPD0538_3_A09) (Friedel et al. 2007) and aggregated with outbred ICR morula. Following confirmation of germline transmission, mice bearing the $n S R 100^{10 x}$ allele were maintained on a $557 \mathrm{Bl} / 6 \mathrm{~N}$ background and crossed with the B6.C- $\mathrm{Tg}(\mathrm{CMV}$-cre $) 1 \mathrm{Cgn} / \mathrm{J}$ line from the Jackson Laboratory. Excision of exons 7 and 8 in the resulting $n S R 100^{+/ \Delta 7-8}$ mice was confirmed by PCR and sequencing.

We attempted to generate mice lacking the partial $(25-\mathrm{kDa})$ polypeptide detected in the $n S R 100^{\Delta 7-8 / \Delta 7-8}$ strain (Fig. 1) by removing both the Frt site-flanked LacZ reporter and exons 7 and 8 by sequential Flpase and Cre recombinase crosses (Supplemental Fig. S9A). However, the resulting $n S R 100^{\Delta G T-e x 8}$ allele produced an nSR100 protein migrating at $\sim 90 \mathrm{kDa}$, which is consistent with the predicted size of a partial nSR100 protein lacking only exons 7 and 8 (Supplemental Fig. S9B). We therefore focused our analyses on the $n S R 100^{\Delta 7-8}$ allele.

\section{Southern blotting}

Southern blotting was performed as described elsewhere (Sambrook and Russell 2001). Briefly, $60 \mu \mathrm{g}$ of mouse genomic tail DNA was digested with AseI and loaded on a $0.8 \%$ agarose gel for each genotype. DNA was transferred to a Hybond XL membrane (GE Healthcare Life Sciences) and hybridized with a ${ }^{32} \mathrm{P}$-dCTP-labeled probe encompassing 456 base pairs (bp) of nSR100 intron 3 upstream of the $5^{\prime}$ homology arm used for homologous recombination of the $n S R 100^{10 x}$ allele.

\section{$R T-P C R$}

Semi-quantitative RT-PCR was performed using the Qiagen onestep RT-PCR kit according to the manufacturer's instructions using $15 \mathrm{ng}$ of total RNA template per $10-\mu \mathrm{L}$ reaction and run on $2 \%$ or $4 \%$ agarose gels. Radiolabeled reactions included $0.05 \mu \mathrm{Ci}$ of ${ }^{32} \mathrm{P}$-dCTP and were run on $6 \%$ Sequagel urea gels (National Diagnostics). Bands were quantified using Image Lab (Bio-Rad) or ImageJ. Primer sequences are available on request.

\section{Antibodies}

For immunoblotting, a polyclonal rabbit antibody (Calarco et al. 2009) raised against amino acids 1-82 of nSR100 was used at 1:5000. Anti-tubulin (T6074, Sigma) was used at 1:5000. For immunostaining, mouse monoclonal anti-neurofilament $(2 \mathrm{H} 3$ conditioned medium, Iowa Developmental Studies Hybridoma Bank) was diluted to 1:50 for whole-mount diaphragm staining and 1:100 for brain section staining. Mouse anti-NeuN (mab377, Millipore), mouse anti-Satb2 (ab51502, Abcam), rabbit anti-Tbr1 (ab31940, Abcam), and chicken polyclonal anti- $\beta$-galactosidase (ab9361, Abcam) were all diluted to 1:500. Chicken antiMAP2 (ab5392, Abcam) was diluted to 1:10,000, mouse anti-Tuj1 (MRB-435P, Covance) was diluted to 1:750, and rabbit anti-Pax6 (PRB-278P, Covance) was diluted to 1:1500. For in situ hybridization, an anti-DIG antibody conjugated to alkaline phosphatase (Roche) was diluted to 1:5000.

\section{In situ hybridization}

In situ hybridization was essentially performed as previously described (Sambrook and Russell 2001). Twenty-micrometer brain sections were post-fixed in $4 \%$ formaldehyde for $10 \mathrm{~min}$ at room temperature. Sections were then prehybridized for 3-6 h at room temperature followed by hybridization with sense or antisense DIG-labeled probes to nSR100 exons 9-13 diluted to 200 $\mathrm{ng} / \mathrm{mL}$ overnight at $60^{\circ} \mathrm{C}$. Alkaline-phosphatase-conjugated anti-DIG antibody was added to slides for $1 \mathrm{~h}$ at room temperature and washed, and an NBT/BCIP solution (Roche) was applied for $1 \mathrm{~h}$ to overnight at room temperature. Sections were cleared in xylene and mounted in Cytoseal XYL (Thermo Scientific).

\section{Immunofluorescence}

For whole-mount diaphragm staining, diaphragms were dissected from E16.5 or E18.5 embryos and fixed in $2 \%$ formaldehyde overnight at $4^{\circ} \mathrm{C}$. Diaphragms were washed in $0.1 \mathrm{M}$ glycine in PBS and blocked overnight at $4{ }^{\circ} \mathrm{C}$ in $0.5 \%$ Triton X-100, 3\% BSA, and $5 \%$ donkey serum with Alexa-594-coupled $\alpha$-bungarotoxin diluted at 1:1500 (Life Technologies). Diaphragms were then further permabilized briefly in $100 \%$ methanol, fixed again in $0.2 \%$ glutaraldehyde and $4 \%$ formaldehyde for $20 \mathrm{~min}$ at room temperature, and then incubated overnight at $4^{\circ} \mathrm{C}$ in blocking buffer with a monoclonal anti-neurofilament antibody diluted to 1:100. After extensive washes, samples were incubated overnight at $4^{\circ} \mathrm{C}$ in blocking buffer with an Alexa- 488 anti-mouse antibody diluted to 1:500 (Life Technologies).

For immunofluorescence microscopy of cortical sections, embryonic mouse brains were dissected and fixed in $4 \%$ formaldehyde for $60 \mathrm{~min}$ at $4^{\circ} \mathrm{C}$. Brains were then sucrose-protected, OCT-embedded (Tissue-Tek), frozen, and coronally sectioned to $16 \mu \mathrm{m}$. Sections were blocked and permeabilized in 5\% BSA and $0.3 \%$ Triton X-100 in PBS with or without M.O.M. blocking reagent (Vector Laboratories) for $60 \mathrm{~min}$ at room temperature. All primary antibodies were incubated overnight at $4^{\circ} \mathrm{C}$ with or without M.O.M. protein concentrate. Secondary antibodies were goat anti-mouse, anti-rabbit, or anti-chicken coupled to Alexa-488, Alexa-568, or Alexa-594 dyes, all diluted to 1:500 and incubated for $60 \mathrm{~min}$ at room temperature with or without M.O.M. protein concentrate. Stained sections were mounted in VectaShield mounting medium with DAPI (Vector Laboratories).

\section{EdU labeling}

Pregnant dams were injected with $0.1 \mathrm{mg} / \mathrm{g}$ EdU at E12.5. Embryos were harvested at E18.5, and brains were dissected, fixed, and 
cryosectioned as described above. Immunostaining using an antibody to Tbrl was first performed as described above. EdU ${ }^{+}$ cells were then stained using the Click-IT Alexa Fluor-488 kit (Life Technologies) according to the manufacturer's protocol.

\section{Quantification of phenotypic data}

For neurite length measurements on whole-mount diaphragms, tracings were generated with the NeuronJ plug-in for ImageJ. Right branches on the ventral and dorsal parts of the diaphragm were measured and counted. For NMJs, a $475-\mu \mathrm{m}$-long region was selected over the ventrally projecting left primary branch, and NMJs were quantified using the ITCN plug-in in ImageJ. The dispersion of NMJs was measured as the average width of the NMJ band at three different levels of the same region of interest. Numbers of cells were counted using the ITCN plug-in over $300-\mu \mathrm{m}$ radial unit regions for $\mathrm{Tbr}^{+}{ }^{+}, \mathrm{Satb}_{2}{ }^{+}, \mathrm{NeuN}^{+}$, and $\mathrm{Pax}^{+}$ cells and a 750- $\mu \mathrm{m}$ radial unit region for EdU ${ }^{+}$cells. Cells and layers were quantified using three sections from each brain. SVZ thickness was measured relative to the total thickness of the cerebral cortex from the lateral ventricle to the surface of layer I.

\section{RNA-seq analysis}

A first replicate consisted of total RNA extracted from cerebral cortices and hippocampi dissected from five wild-type and five $n S R 100^{\Delta 7-8 / \Delta 7-8}$ mutant brains at E18.5. RNA was pooled by genotype and prepared using the Illumina TruSeq mRNA kit, and cortical and hippocampal samples were sequenced on different runs of Illumina HiSeq2500 (average of 93 million 100-nt single end and 100-nt paired-end reads for each run, respectively) (see Supplemental Table S4 for details). A second replicate was processed as above and consisted of total RNA pooled from three wild-type or three mutant brains at E18.5. An average of $\sim 90$ million 100-nt paired-end reads was sequenced for each sample (Supplemental Table S4).

Transcriptome-wide AS and gene expression profiling was performed using our recently described pipeline (vast-tools) (Irimia et al. 2014). vast-tools uses reads mapping to exon-exon (or exon-intron) junctions (EEJ or EIJ) only to accurately detect and quantify all types of AS events, including 3- to 27-nt microexons. Gene expression levels were measured using the cRPKM metric (Labbe et al. 2012).

PSI/PIR/PSU of AS events for the eight samples were paired into four replicates (wild-type and $n S R 100^{\Delta 7-8 / \Delta 7-8}$ for two cortex and two hippocampus samples), and a paired $t$-test was performed for AS events with enough read coverage in all eight samples. A given AS event was considered to have sufficient read coverage in a particular RNA-seq sample according to the following criteria (Irimia et al. 2014):

- For cassette exons (except for those quantified using the microexon pipeline), (1) $\geq 10$ actual reads (i.e., before mappability correction) mapped to the sum of exclusion EEJs or (2) $\geq 10$ actual reads mapped to one of the two inclusion EEJs and five or more mapped to the other inclusion EEJ.

- For microexons, $(1) \geq 10$ actual reads mapped to the sum of exclusion EEJs or $(2) \geq 10$ actual reads mapped to the sum of inclusion EEJs.

- For IR, (1) $\geq 10$ actual reads mapped to the sum of skipping EEJs or (2) $\geq 10$ actual reads mapped to one of the two inclusion EIJs and five or more mapped to the other inclusion EIJ.

- For Alt3 and Alt5, $\geq 10$ actual reads mapped to the sum of all EEJs involved in the specific event.
For an AS event to be considered differentially regulated between wild-type and $n S R 100^{\Delta 7-8 / \Delta 7-8}$ brains, we required a $P$-value of $<0.05$ in the $t$-test and an average $\Delta$ PSI (between the four paired replicates) of at least $10 \%$.

All RNA-seq data have been deposited in the Gene Expression Omnibus database under accession number GSE65818.

\section{Functional enrichment analyses}

Ensembl gene IDs for the cassette exons and microexons that showed significantly increased skipping in $n S R 100^{\Delta 7-8 / \Delta 7-8}$ brains (137 genes in total) were uploaded to DAVID (http://david.abcc. ncifcrf.gov; Huang et al. 2009) to perform functional enrichment analyses using a stringent background consisting of 10,968 genes with expression of at least cRPKM $>2$ in one of the brain samples. Only GO_FAT terms and KEGG (Kyoto Encyclopedia of Genes and Genomes) pathways were used for clustering analyses.

\section{Primary neuronal cultures}

Protocols for culturing primary mouse neurons were kindly provided by Dr. Antony Boucard and Dr. Thomas Sudhof (Stanford University) (Boucard et al. 2005). Briefly, hippocampal or cortical neurons were harvested from wild-type or $n S R 100^{\Delta 7-8 / \Delta 7-8}$ mice at E18.5 and plated on glass coverslips coated with 2\% Matrigel (Corning) in plating medium consisting of MEM (51200-038, Life Technologies) supplemented with $0.5 \%$ glucose, $0.2 \mathrm{mg} /$ $\mathrm{mL} \mathrm{NaHCO} 3,0.1 \mathrm{mg} / \mathrm{mL}$ transferrin (616420, Calbiochem), $10 \%$ fetal bovine serum (FBS) (SH30396.03, GE Life Sciences), $2 \mathrm{mM}$ L-glutamine (12403-010, Life Technologies), and $25 \mu \mathrm{g} /$ $\mathrm{mL}$ insulin (I-6634, Sigma). Plating medium was changed at DIV1 to growth medium consisting of MEM supplemented with $0.5 \%$ glucose, $0.2 \mathrm{mg} / \mathrm{mL} \mathrm{NaHCO}, 0.1 \mathrm{mg} / \mathrm{mL}$ transferrin, $5 \%$ FBS, 0.5 mM L-glutamine, and 2\% B-27 supplement (17504044, Life Technologies). Dissociated neurons were transfected prior to plating using the Amaxa Nucleofector kit (VPG-1001, Lonza) using $\sim 5 \times 10^{4}$ cells and $10 \mu \mathrm{g}$ of plasmid DNA per transfection. Cells from the same embryos were aliquoted and transfected individually with each construct. Unc13_skp, Unc13_inc, and nSR100 were cloned upstream of the RFP coding sequence and placed under the control of the CAGGS promoter. The length of neurites was quantified using the NeuronJ plug-in for ImageJ.

\section{Acknowledgments}

We thank Marina Gertsenstein, Sandra Tondat, Monica Pereira, Christina Dalrymple, Jorge Cabezas, Jessica Raponi, and Amanda Leonelli at the Toronto Centre for Phenogenomics for assistance with the generation and maintenance of mutant mouse strains. Dax Torti and Danica Leung of the Donnelly Sequencing Centre are gratefully acknowledged for sequencing samples. We also thank Jonathan Ellis for generating constructs used in primary neuronal cultures, and members of the Blencowe and Cordes laboratories for helpful discussions and comments on the manuscript. This research was supported by grants from the Canadian Institutes of Health Research (CIHR; MOP-67011, MOP-14609, and MOP-111199| to B.J.B. and S.P.C. M.I. was supported by a long-term Fellowship from the Human Frontiers Science Program Organization. M.Q.-V. was supported by CIHR Banting and Best Scholarship and Ontario Graduate Scholarship. B.J.B. holds the Banbury Chair of Medical Research at the University of Toronto. 


\section{References}

Akbarian S, Bunney WE Jr, Potkin SG, Wigal SB, Hagman JO, Sandman CA, Jones EG. 1993. Altered distribution of nicotinamide-adenine dinucleotide phosphate-diaphorase cells in frontal lobe of schizophrenics implies disturbances of cortical development. Arch Gen Psychiatry 50: 169-177.

Barbosa-Morais NL, Irimia M, Pan Q, Xiong HY, Gueroussov S, Lee LJ, Slobodeniuc V, Kutter C, Watt S, Colak R, et al. 2012. The evolutionary landscape of alternative splicing in vertebrate species. Science 338: 1587-1593.

Boucard AA, Chubykin AA, Comoletti D, Taylor P, Sudhof TC. 2005. A splice code for trans-synaptic cell adhesion mediated by binding of neuroligin 1 to $\alpha$ - and $\beta$-neurexins. Neuron 48: 229-236.

Braunschweig U, Gueroussov S, Plocik AM, Graveley BR, Blencowe BJ. 2013. Dynamic integration of splicing within gene regulatory pathways. Cell 152: 1252-1269.

Braunschweig U, Barbosa-Morais NL, Pan Q, Nachman EN, Alipanahi B, Gonatopoulos-Pournatzis T, Frey B, Irimia M, Blencowe BJ. 2014. Widespread intron retention in mammals functionally tunes transcriptomes. Genome Res 24: 17741786.

Broeke JHP, Roelandse M, Luteijn MJ, Boiko T, Matus A, Toonen RF, Verhage M. 2010. Munc18 and Munc13 regulate early neurite outgrowth. Biol Cell 102: 479-488.

Buckanovich RJ, Posner JB, Darnell RB. 1993. Nova, the paraneoplastic Ri antigen, is homologous to an RNA-binding protein and is specifically expressed in the developing motor system. Neuron 11: 657-672.

Buljan M, Chalancon G, Eustermann S, Wagner GP, Fuxreiter M, Bateman A, Babu MM. 2012. Tissue-specific splicing of disordered segments that embed binding motifs rewires protein interaction networks. Mol Cell 46: 871-883.

Calarco JA, Superina S, O'Hanlon D, Gabut M, Raj B, Pan Q, Skalska U, Clarke L, Gelinas D, van der Kooy D, et al. 2009. Regulation of vertebrate nervous system alternative splicing and development by an SR-related protein. Cell 138: 898-910.

Caviness VSJ. 1982. Neocortical histogenesis in normal and reeler mice: a developmental study based upon $[3 \mathrm{H}]$ thymidine autoradiography. Brain Res 256: 293-302.

Champagnat J, Morin-Surun MP, Bouvier J, Thoby-Brisson M, Fortin G. 2011. Prenatal development of central rhythm generation. Respir Physiol Neurobiol 178: 146-155.

Chedotal A. 2007. Slits and their receptors. Adv Exp Med Biol 621: $65-80$.

Chen M, Manley JL. 2009. Mechanisms of alternative splicing regulation: insights from molecular and genomics approaches. Nat Rev Mol Cell Biol 10: 741-754.

Chen Z, Gore BB, Long H, Ma L, Tessier-Lavigne M. 2008. Alternative splicing of the Robo3 axon guidance receptor governs the midline switch from attraction to repulsion. Neuron 58: 325-332.

Cheung HN, Dunbar C, Morotz GM, Cheng WH, Chan HY, Miller CC, Lau KF. 2014. FE65 interacts with ADP-ribosylation factor 6 to promote neurite outgrowth. FASEB I 28: 337-349.

Deol MS, Gluecksohn-Waelsch S. 1979. The role of inner hair cells in hearing. Nature 278: 250-252.

Donahoo AL, Richards LJ. 2009. Understanding the mechanisms of callosal development through the use of transgenic mouse models. Semin Pediatr Neurol 16: 127-142.

Ellis JD, Barrios-Rodiles M, Colak R, Irimia M, Kim T, Calarco JA, Wang X, Pan Q, O'Hanlon D, Kim PM, et al. 2012. Tissue-specific alternative splicing remodels protein-protein interaction networks. Mol Cell 46: 884-892.
Feng Y, Walsh CA. 2004. Mitotic spindle regulation by Nde1 controls cerebral cortical size. Neuron 44: 279-293.

Friedel RH, Seisenberger C, Kaloff C, Wurst W. 2007. EUCOMM - the European conditional mouse mutagenesis program. Brief Funct Genomic Proteomic 6: 180-185.

Gao P, Sultan KT, Zhang XJ, Shi SH. 2013. Lineage-dependent circuit assembly in the neocortex. Development 140: 2645-2655.

Gehman LT, Meera P, Stoilov P, Shiue L, O'Brien JE, Meisler MH, Ares MJr, Otis TS, Black DL. 2012. The splicing regulator Rbfox 2 is required for both cerebellar development and mature motor function. Genes Dev 26: 445-460.

Giraudin A, Le Bon-Jego M, Cabirol MJ, Simmers J, Morin D. 2012. Spinal and pontine relay pathways mediating respiratory rhythm entrainment by limb proprioceptive inputs in the neonatal rat. J Neurosci 32: 11841-11853.

Huang DW, Sherman BT, Lempicki RA. 2009. Bioinformatics enrichment tools: paths toward the comprehensive functional analysis of large gene lists. Nucleic Acids Res 37: 1-13.

Irimia M, Weatheritt RJ, Ellis JD, Parikshak NN, GonatopoulosPournatzis T, Babor M, Quesnel-Vallieres M, Tapial J, Raj B, O'Hanlon D, et al. 2014. A highly conserved program of neuronal microexons is misregulated in autistic brains. Cell 159: 1511-1523.

Kwan KY, Lam MM, Krsnik Z, Kawasawa YI, Lefebvre V, Sestan N. 2008. SOX5 postmitotically regulates migration, postmigratory differentiation, and projections of subplate and deeplayer neocortical neurons. Proc Natl Acad Sci 105: 1602116026.

Labbe RM, Irimia M, Currie KW, Lin A, Zhu SJ, Brown DD, Ross EJ, Voisin V, Bader GD, Blencowe BJ, et al. 2012. A comparative transcriptomic analysis reveals conserved features of stem cell pluripotency in planarians and mammals. Stem Cells 30: 1734-1745.

Li Q, Lee JA, Black DL. 2007. Neuronal regulation of alternative pre-mRNA splicing. Nat Rev Neurosci 8: 819-831.

Li Q, Zheng S, Han A, Lin CH, Stoilov P, Fu XD, Black DL. 2014. The splicing regulator PTBP2 controls a program of embryonic splicing required for neuronal maturation. eLife 3: e01201.

Li YI, Sanchez-Pulido L, Haerty W, Ponting CP. 2015. RBFOX and PTBP1 proteins regulate the alternative splicing of micro-exons in human brain transcripts. Genome Res 25: 1-13.

Licatalosi DD, Yano M, Fak JJ, Mele A, Grabinski SE, Zhang C, Darnell RB. 2012. Ptbp2 represses adult-specific splicing to regulate the generation of neuronal precursors in the embryonic brain. Genes Dev 26: 1626-1642.

Lipscombe D. 2005. Neuronal proteins custom designed by alternative splicing. Curr Opin Neurobiol 15: 358-363.

Lipscombe D, Allen SE, Toro CP. 2013a. Control of neuronal voltage-gated calcium ion channels from RNA to protein. Trends Neurosci 36: 598-609.

Lipscombe D, Andrade A, Allen SE. 2013b. Alternative splicing: functional diversity among voltage-gated calcium channels and behavioral consequences. Biochim Biophys Acta 1828: 1522-1529.

Mellen NM, Thoby-Brisson M. 2012. Respiratory circuits: development, function and models. Curr Opin Neurobiol 22: 676-685.

Merkin J, Russell C, Chen P, Burge CB. 2012. Evolutionary dynamics of gene and isoform regulation in mammalian tissues. Science 338: 1593-1599.

Nakano Y, Jahan I, Bonde G, Sun X, Hildebrand MS, Engelhardt JF, Smith RJ, Cornell RA, Fritzsch B, Banfi B. 2012. A mutation in the Srrm 4 gene causes alternative splicing defects and deafness in the Bronx waltzer mouse. PLoS Genet 8: e1002966. 
Norris AD, Calarco JA. 2012. Emerging roles of alternative premRNA splicing regulation in neuronal development and function. Front Neurosci 6: 122.

Ohnishi T, Shirane M, Hashimoto Y, Saita S, Nakayama KI. 2014. Identification and characterization of a neuron-specific isoform of protrudin. Genes Cells 19: 97-111.

Ovadia G, Shifman S. 2011. The genetic variation of RELN expression in schizophrenia and bipolar disorder. PLoS One 6: e19955.

Paul LK, Brown WS, Adolphs R, Tyszka JM, Richards LJ, Mukherjee P, Sherr EH. 2007. Agenesis of the corpus callosum: genetic, developmental and functional aspects of connectivity. Nat Rev Neurosci 8: 287-299.

Raj B, O'Hanlon D, Vessey JP, Pan Q, Ray D, Buckley NJ, Miller FD, Blencowe BJ. 2011. Cross-regulation between an alternative splicing activator and a transcription repressor controls neurogenesis. Mol Cell 43: 843-850.

Raj B, Irimia M, Braunschweig U, Sterne-Weiler T, O'Hanlon D, Lin ZY, Chen GI, Easton LE, Ule J, Gingras AC, et al. 2014. A global regulatory mechanism for activating an exon network required for neurogenesis. Mol Cell 56: 90-103.

Ross CA, Margolis RL, Reading SA, Pletnikov M, Coyle JT. 2006. Neurobiology of schizophrenia. Neuron 52: 139-153.

Ruggiu M, Herbst R, Kim N, Jevsek M, Fak JJ, Mann MA, Fischbach G, Burden SI, Darnell RB. 2009. Rescuing Z+ agrin splicing in Nova null mice restores synapse formation and unmasks a physiologic defect in motor neuron firing. Proc Natl Acad Sci 106: 3513-3518.

Rusconi F, Paganini L, Braida D, Ponzoni L, Toffolo E, Maroli A, Landsberger N, Bedogni F, Turco E, Pattini L, et al. 2014. LSD1 neurospecific alternative splicing controls neuronal excitability in mouse models of epilepsy. Cereb Cortex doi: 10.1093/cercor/bhu070.
Sambrook J, Russell DW. 2001. Molecular cloning: a laboratory manual. Cold Spring Harbor Laboratory Press, Cold Spring Harbor, NY.

Shen H, Green MR. 2004. A pathway of sequential arginine-serine-rich domain-splicing signal interactions during mammalian spliceosome assembly. Mol Cell 16: 363-373.

Stoner R, Chow ML, Boyle MP, Sunkin SM, Mouton PR, Roy S, Wynshaw-Boris A, Colamarino SA, Lein ES, Courchesne E. 2014. Patches of disorganization in the neocortex of children with autism. N Engl J Med 370: 1209-1219.

Tsyba L, Gryaznova T, Dergai O, Dergai M, Skrypkina I, Kropyvko S, Boldyryev O, Nikolaienko O, Novokhatska O, Rynditch A. 2008. Alternative splicing affecting the SH3A domain controls the binding properties of intersectin 1 in neurons. Biochem Biophys Res Commun 372: 929-934.

UleJ, Darnell RB. 2006. RNA binding proteins and the regulation of neuronal synaptic plasticity. Curr Opin Neurobiol 16: 102-110.

Unni DK, Piper M, Moldrich RX, Gobius I, Liu S, Fothergill T, Donahoo AL, Baisden JM, Cooper HM, Richards LJ. 2012. Multiple Slits regulate the development of midline glial populations and the corpus callosum. Dev Biol (N Y 1985) 365: 36-49.

Wu JY, Maniatis T. 1993. Specific interactions between proteins implicated in splice site selection and regulated alternative splicing. Cell 75: 1061-1070.

Yang YY, Yin GL, Darnell RB. 1998. The neuronal RNA-binding protein Nova-2 is implicated as the autoantigen targeted in POMA patients with dementia. Proc Natl Acad Sci 95: 13254-13259.

Yano M, Hayakawa-Yano Y, Mele A, Darnell RB. 2010. Nova2 regulates neuronal migration through an RNA switch in disabled-1 signaling. Neuron 66: 848-858.

Zheng S, Black DL. 2013. Alternative pre-mRNA splicing in neurons: growing up and extending its reach. Trends Genet 29: 442-448. 


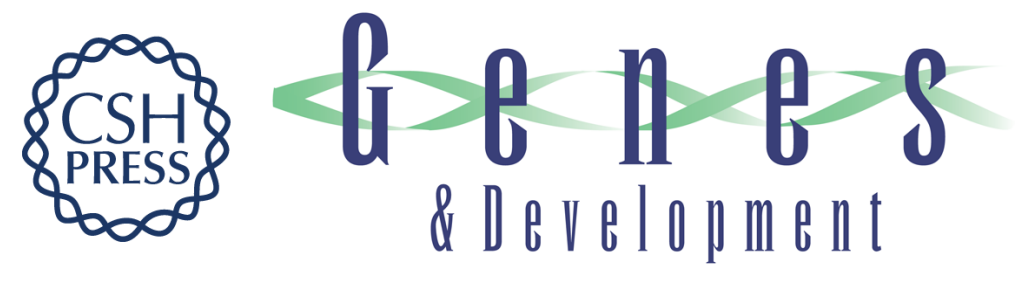

\section{Essential roles for the splicing regulator nSR100/SRRM4 during nervous system development}

Mathieu Quesnel-Vallières, Manuel Irimia, Sabine P. Cordes, et al.

Genes Dev. 2015, 29:

Access the most recent version at doi:10.1101/gad.256115.114

\section{Supplemental http://genesdev.cshlp.org/content/suppl/2015/04/01/29.7.746.DC1 Material}

References This article cites 55 articles, 11 of which can be accessed free at: http://genesdev.cshlp.org/content/29/7/746.full.html\#ref-list-1

Creative This article is distributed exclusively by Cold Spring Harbor Laboratory Press for the first Commons six months after the full-issue publication date (see

License http://genesdev.cshlp.org/site/misc/terms.xhtml). After six months, it is available under a Creative Commons License (Attribution-NonCommercial 4.0 International), as described at http://creativecommons.org/licenses/by-nc/4.0/.

Email Alerting Receive free email alerts when new articles cite this article - sign up in the box at the top Service right corner of the article or click here.

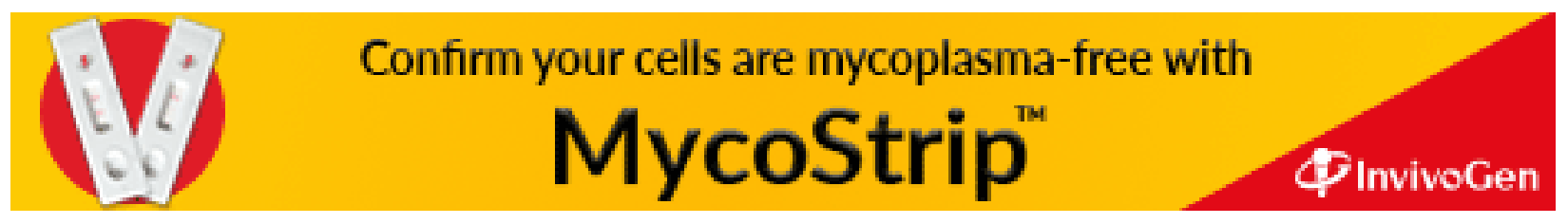

